\title{
A transformação do sofrimento em adoecimento: do nascimento da clínica à psicodinâmica do trabalho
}

\author{
The transformation process of suffering \\ into illness: from the birth of the clinic \\ to the psychodynamic work
}

Luiz Carlos Brant 1

Carlos Minayo-Gomez 1
1 Centro de Estudo da Saúde do Trabalhador e Ecologia Humana, Escola Nacional de Saúde Pública, Fiocruz. Av. Leopoldo Bulhões 1480, Manguinhos, 21041-410, Rio de Janeiro RJ. interfaz@interfaz.com.br
Abstract Starting from the conceptual differentiation of suffering, pain and illness, we tried to find, through previous literary works and interviews with workers and managers, elements to demonstrate the existence of a transformation process that turns suffering into illness in the work management area. This process is not only related with the production and reproduction of discourses originally from the scientific medicine, but also with a set of practices supported, in the present time, by the occupational medicine. The evidences of our research point to the attempt of silencing this suffering and to the existence of an illness promotion culture in the company space. This situation involves workers, health professionals, and managers with the complicity of the families whose workers are identified as patients. However, some cases have shown resistance to this process, which constitutes a real counter-illness movement. After these elements we came to the conclusion that, during these two centuries of scientific medicine, despite the desire of changing and renewing practices and investments, iatrogenic acts and violence still have been done in the name of science, of health, and of workers wellbeing.

Key words Psychic suffering, Worker's health, Psychodynamic of work, Occupational health
Resumo Tem-se como pressuposto que o processo de transformação do sofrimento em adoecimento, na gestão do trabalho, está relacionado não apenas com a produção e reprodução de discursos originários da medicina científica, mas também com um conjunto de práticas sustentadas, na atualidade, pela medicina ocupacional. Partindo da diferenciação conceitual entre sofrimento, dor e adoecimento, buscou-se na literatura e em entrevistas com trabalhadores e gestores elementos para demonstrar a existência deste processo. Constatou-se uma tentativa de silenciamento do sofrimento e uma cultura da promoção do adoecimento no espaço da empresa, envolvendo trabalhadores, profissionais da saúde e os gestores com a cumplicidade de famílias de trabalhadores identificados como pacientes. No entanto, alguns casos oferecem resistência ao processo, constituindo um verdadeiro movimento do contra-adoecimento. Conclui-se que, nesses dois séculos de "medicina científica", embora houvesse desejo de mudança, renovação das práticas e investimentos das mais diversas ordens, atos iatrogênicos e violências foram e são cometidos ainda em nome da ciência, da saúde e do bem-estar dos trabalhadores.

Palavras-chave Sofrimento psíquico, Saúde do trabalhador, Psicodinâmica do trabalho, Saúde ocupacional 


\section{Introdução}

$\mathrm{Na}$ atualidade, parece existir uma tendência de banir o sofrimento do mundo do trabalho e desconsiderá-lo uma dimensão contingente à produção. Dar visibilidade ao processo de transformação do sofrimento em adoecimento, no âmbito da gestão do trabalho, se faz importante à medida que ele explicita a existência de situações políticas (dominação e resistência), de gozo (mesclagem de prazer e dor) e econômicas (prescrição e consumo abusivos de medicalização). O ato de criar implica rupturas. Não há como "fazer um omelete sem quebrar ovos". Da mesma forma, não há criação sem corte, portanto, sem sofrimento. É possível observar, no interior das organizações, o quanto a tristeza é, imediatamente, nomeada como depressão e o medo, como paranóia, apenas para citar alguns exemplos. Esse adoecimento não se faz sem conseqüências, uma vez que ele discrimina, estigmatiza e exclui. O que abre espaço para a medicalização das manifestações do sofrimento nas empresas através da prescrição indiscriminada, principalmente, de antidepressivos e ansiolíticos. Portanto, evidenciar a transformação do sofrimento em adoecimento significa criticar esse conjunto de práticas que permite a enunciação de determinadas doenças.

Na saúde do trabalhador, como campo de conhecimento e de intervenção, é ampla a literatura sobre trabalho e sofrimento psíquico, como se pode constatar em Merlo (1999), que investigou prazer e sofrimento no trabalho de processamento de dados em Porto Alegre; Palácios (1999 e 1993), que estudou, no Rio de Janeiro, o trabalho de caixa bancário em uma instituição estatal, bem como o trabalho hospitalar e a saúde mental; Oliveira (1998), que pesquisou trabalhadores da saúde em uma unidade hospitalar no Pará; e Jardim (1994), que investigou o processo de trabalho dos pilotos do metrô carioca. No entanto, até onde foi possível pesquisar, sofrimento diferenciado de adoecimento e dor, em termos conceituais, constitui-se uma dimensão pouco investigada.

Ao efetuarmos um estudo acerca do processo de transformação do sofrimento em adoecimento, não buscamos conhecer a etiologia de um determinado sofrimento ou o seu nexo causal com o trabalho, mas sim investigar o destino seguido a partir de sua manifestação nas empresas. Partimos do princípio de que os sujeitos sofrem e manifestam seu sofrimento, em maior ou menor grau, de acordo com o uso que fazem do vocabulário disponível em sua época e da sua inserção social. As práticas lingüísticas produzem e reproduzem manifestações diversas do sofrimento. Existem várias maneiras de se experimentar e manifestá-lo: pela fala, sonhos, corpo, atos e pelo trabalho. Uma vez expresso, o sofrimento recebeu diferentes significações e destinos ao longo da história. De símbolo do pecado judaico-cristão à patologia da ciência moderna, passando pela bruxaria medieval, o sofrimento sempre exigiu do homem uma explicação lógica, quanto mais estranheza a sua manifestação provocava na comunidade.

Sob essas bases, buscou-se: 1) traçar uma breve trajetória que vai do nascimento da clínica, no início do século 19 , à psicodinâmica dejouriana, em meados dos século 20, servindo-se basicamente de Foucault (1998 e 1979); Herzlicch e Pierret (1987), Costa (1989a; 1989b) e Dejours (1992; 1994 e 1996); 2) diferenciar conceitualmente sofrimento, dor e adoecimento, recorrendo a Freud (1920), aos artigos de Ricouer (1994) e de Marquez (1994); 3) assinalar criticamente o lugar que o sofrimento ocupa na teoria dejouriana; 4) dar voz aos trabalhadores como forma de evidenciar os mecanismos de submissão e resistência. Para este último, utilizaram-se recortes de entrevistas abertas, de uma pesquisa que tem por objetivo investigar os destinos das manifestações do sofrimento, no âmbito de uma empresa de grande porte, do setor de serviços, situada na região metropolitana de Belo Horizonte. Foram entrevistados trabalhadores e familiares; gestores e profissionais da saúde. Para a análise dos relatos obtidos recorreu-se ao método Análise de Conteúdo (Bardin, 1977; Triviños, 1987; Minayo, 1996).

\section{Sofrimento, sujeito e dor}

É importante reconhecer que o sofrimento não tem uma manifestação única para todos os indivíduos de uma mesma família, cultura ou período histórico. O que é sofrimento para um, não é, necessariamente, para outro, mesmo quando submetidos às mesmas condições ambientais adversas. Ou ainda, aquilo que é sofrimento para alguém, pode ser prazer para outro e vice-versa. Um acontecimento, como algo capaz de provocar um espanto, em um determinado momento pode significar sofrimento; em outro, pode ser vivenciado como satisfação. 
Resta ainda lembrar que no sofrimento é possível encontrar uma mesclagem de prazer e dor, simultaneamente (Brant, 2001a). Assim, essa condição básica do ser no mundo não pode ser definida apenas a partir do acontecimento. $\mathrm{O}$ sofrimento depende da significação que assume no tempo e no espaço, bem como no corpo que ele toca produzindo algo "além do princípio do prazer". O homem sofre porque passa a perceber a sua finitude; o que faz do sofrimento uma dimensão não apenas psicológica, mas, sobretudo, existencial. Falar em tempo exige também falar em memória. A memória do sofrimento é o elemento capaz de implicar o ser na preservação da vida; eis uma importante função do sofrimento na construção do sujeito. Estar implicado significa acreditar na promessa de um futuro, sinalizando algo para além do imediatamente presente. Portanto, o sofrimento está relacionado com um saber acerca da existência que não se sabe todo, no que difere o homem do animal.

O sofrimento, como uma dimensão intolerável nas empresas, pactua com a linguagem que, além de representar, tem a função de criar laços discursivos entre os sujeitos, as coisas ao redor, de modo a estruturar um universo de sentido minimamente compatível com a vida (Costa, 1992). Esta asserção não implica desconsiderar o corpo, pois o sofrimento também tem uma inscrição nele, compondo uma geografia marcada por relevos atravessados por prazer e dor, nem sempre passível de ser expressa em palavras. As fronteiras entre sofrimento, não-sofrimento e sofrimento-prazer são imprecisas, vagas, e se superpõem em camadas indiscerníveis, muitas vezes inefáveis. $\mathrm{O}$ manifestado depende da modalidade pela qual se introjetou a linguagem e aprendeu a sentir e a nomear a experiência como angústia, dor, prazer ou satisfação. A maneira como utiliza a linguagem para lidar com as solicitações do outro define os atos, que podem ser de submissão, desobediência e contestação. O sujeito é, portanto, produto da contingência da linguagem, do desejo e do conjunto de dispositivos presentes no seu espaço institucional.

Para Freud (1920), o sofrimento é o estado de expectativa diante do perigo e da preparação para ele, ainda que seja um perigo desconhecido (angústia); ou medo quando ele é conhecido; ou susto quando o sujeito topa com um perigo sem estar preparado para enfrentálo. Portanto, o sofrimento se configura como uma reação, uma manifestação da insistência em viver em um ambiente que, na maioria das vezes, não lhe é favorável. Assim, procurar-se-á abordar o sofrimento a partir do sujeito, que pode ser definido como: efeito das práticas lingüisticas, uma decorrência do uso de nossos vocabulários. Somos aquilo que a linguagem nos permite ser, acreditamos naquilo que ela permite acreditar, só ela pode fazer-nos acreditar em algo do outro como familiar, natural ou, pelo contrário, repudiá-lo como estranho, antinatural e ameaçador (Costa, 1992).

O sofrimento, marcado por um "estado de expectativa diante do perigo", pressupõe a existência de um registro, de um código lingüístico que permite identificar, nomear e comunicar determinadas percepções avaliadas como ameaça. Na preparação para enfrentá-lo, é possível encontrar a dimensão que define o sujeito, a sua submissão a determinados discursos. É a inserção num discurso que permite a representação de um acontecimento como perigoso ou não, portanto capaz de desencadear sofrimento ou não. O perigo pode estar, concretamente, no ambiente e ser representado como ameaça, uma mesclagem de experiência e memória, ou pode estar interiorizado, apenas como fruto do imaginário.

Do ponto de vista conceitual, sofrimento e dor não se confundem, mas também não se distinguem com facilidade, da mesma forma que não se pode separar a frente e o verso de uma folha de papel. O que não nos autoriza afirmar a existência de uma relação de complementaridade entre eles. Na realidade, há um estreito e tênue limite entre os dois termos que estaria relacionado com um esgarçamento etimológico e semântico, como muito apropriadamente observa Marquez (1994). Fruto de uma visão dicotômica, a palavra sofrimento tem sido associada ao psíquico, ao mental ou à alma, enquanto a palavra dor, geralmente, é remetida a algo localizado no corpo. Tanto é, que diante da afirmação "estou com dor", a pergunta imediata é: onde? Ao se referir à existência de dois tipos de dor, a seguinte fala de um dos supervisores entrevistados comporta alguns elementos que nos possibilitam melhor pensar a diferenciação entre dor e sofrimento: $E u$ bebo; quando caio, a dor da culpa dói mais que a dor do corpo. Há uma dor física e há uma dor mental. A dor do corpo não dói tanto quanto a dor da alma (DV, 49 anos). Mesmo sob a alegação de portar uma concepção fragmentada do mundo sensível, é possível constatar, na fala do entrevistado, a indicação da existência de expe- 
riências que se diferenciam e que são vivenciadas, espacialmente, em diferentes regiões. Qualquer que seja a denominação e a localização dessa dimensão humana, no físico ou na alma, pouco importa; o interessante é perceber a existência de uma diferença que já está assinalada, no mínimo, no plano da linguagem.

Portanto, sofrimento e dor não podem ser reduzidos à dimensão corporal ou lingüística como propõe Ricouer (1994) quando afirma que o termo dor está destinado às manifestações que têm lugar em órgãos específicos do corpo ou no corpo como um todo. Ou seja, a dor estaria marcada por um solipsismo que assinala a prevalência da realidade imaginária do eu, portanto, não implicaria a dimensão da alteridade, reflexividade e linguagem, como acontece no sofrimento. Nesses termos, a questão exige um cuidadoso estudo de modo que se possa avançar a compreensão do ser no mundo do trabalho, para além do corpo e da linguagem. Diferenciação fundamental quando pensamos na existência de um processo de transformação do sofrimento em adoecimento nas empresas. Pois, em última instância, essa diferenciação pode definir pela permanência ou afastamento do trabalhador; ou seja, em termos de saúde ocupacional, ele está doente ou não? É tudo que alguns médicos do trabalho definem; o que constitui um enorme reducionismo do processo saúde-doença-cuidado. Compreender a diferença entre sofrimento e dor e a sua articulação com o sujeito, como construto psicanalítico, pode colaborar no grande desafio que é estabelecer o diagnóstico diferencial entre os distúrbios osteo-musculares relacionados ao trabalho (DORT) e fibromialgia. $\mathrm{E}$ assim compreender que mesmo na ausência de um comprometimento neuromuscular, resultado dos mais avançados exames de imagens, é possível a existência da dor no sujeito. O que não significa, necessariamente, manipulação histérica ou má-fé do trabalhador. Existe algo para além da doença ou da não-doença; e isso o médico jamais poderá esquecer, sob pena de operar um imenso reducionismo na sua prática e silenciar o sofrimento do trabalhador, adoecendo e estigmatizando-o.

\section{Silenciando o sofrimento e promovendo o adoecimento: uma trajetória histórica}

A transformação do sofrimento em adoecimento pode ser compreendida através do lon- go percurso do "poder disciplinar" que foi aperfeiçoado como uma nova técnica de gestão dos homens. A partir do século 18, procurouse investigar de que maneira os gestos são feitos, qual o mais eficaz, rápido e mais ajustado, conforme descrição de Foucault (1979). Na gestão do trabalho pós-industrial, a disciplina como técnica de exercício do poder tem por função não mais controlar os gestos e os corpos, mas o pensamento, a criação e as manifestações do sofrimento. Os mecanismos de gestão disciplinar do corpo, que exigiam uma acirrada vigilância de olhares sobre os trabalhadores, nas primeiras décadas do século 20 , tornaram-se incompatíveis com a moderna organização. Na contemporaneidade, já não faz sentido que o indivíduo seja observado e cronometrado regularmente. No entanto, a necessidade de controlar parece exigir medidas disciplinares cada vez mais refinadas. Como acontece, por exemplo, com o processo saúde-doençacuidado, que, no interior das fábricas pós-industriais, tornou-se uma dessas medidas. Em conseqüência disso, observam-se sutis tentativas de destituição do trabalhador da sua condição de sujeito, para transformá-lo em paciente. Processo esse fundado numa relação muito singular, que envolve profissionais da saúde, gestores, trabalhadores e alguns de seus familiares.

Ao reportarmo-nos ao século 19, é possível verificar, através das obras de Foucault (1998; 1979) e Herzlicch \& Pierret (1987), o início da ruptura que se estabeleceu no saber médico e que transformou o sujeito em paciente. Com o advento da medicina científica, novas formas de conhecimento e novas práticas institucionais tornaram o paciente desvinculado do seu sofrimento. Nessa época, para conhecer a "verdade do fato patológico", o médico precisou abstrair o sujeito, pois sua disposição, temperamento, fala, idade, modos de vida perturbavam a identificação da doença, segundo o desenho nosográfico preestabelecido. Com base em uma formação mecanicista, o papel dessa lógica médica era neutralizar essas perturbações, manter o sujeito distante para que a configuração ideal da doença aparecesse aos olhos do médico, no abismo que se instaurava entre eles.

Nessa nova racionalidade, o olhar clínico foi dirigido para o corpo, representado como lugar da doença. Houve um quase silenciamento do paciente que, em vão, tentava falar de seu sofrimento e daquilo que imaginava ser o seu mal. A doença foi retirada de sua metafísica da 
maldade, da qual tinha sido parte durante séculos e passou a ocupar um estado corporal que permitiu sua leitura pela ciência. Ao instaurar o fim de uma concepção religiosa e individual da doença, acabou-se tamponando as reações de sofrimento do sujeito diante das adversidades ou fragilidade da vida. Os sintomas assumiram os significados de determinantes naturais das doenças, deixando de lado a articulação entre o sujeito e o sofrimento. Assim, os sintomas deixaram de ser representados como tentativa de solução de um conflito, de uma reconciliação do ser, que habita o mundo da vida e é por ele habitado. Perdida a sua condição de "um bem" do sujeito, o sintoma passou a se figurar apenas como sinal de uma patologia. $\mathrm{O}$ sujeito, banido da cosmologia médica, deu lugar ao paciente, representado como um conjunto de órgãos e tecidos. Em suma, essa lógica lançou as bases para a construção da identidade do doente.

Um dos destinos da manifestação do sofrimento, a partir do século 19 , foi o hospital, que surgiu como um espaço de consolidação da identidade de doente, de assistência, segregação e exclusão (Foucault, 1998; 1979). Como uma imensa vitrine, a hospitalização deu visibilidade ao paciente reafirmando-o como doente na família, no trabalho e na comunidade. Uma vez internado, não havia dúvidas de sua condição de doente, mesmo quando não se tinha ainda um diagnóstico. A partir da instituição do hospital, a residência deixaria de ser o lugar onde o sofrimento se manifestava em sua forma possível. Assim, a família perdeu a autoridade sobre a maneira de cuidar do seu ente, que seria doravante isolado e "olhado cientificamente". No hospital, a partir do olhar médico, pretendia-se reparar os excessos ou deficiências das práticas familiares em relação ao processo saúde-doença-cuidado. Introjetada a ordem médica, que desqualificava as práticas curativas familiares, cada vez mais a família se viu obrigada a solicitar atenção médica por se perceber impotente diante das manifestações do sofrimento que foram, imediatamente, representadas como sinais de doença.

$\mathrm{Na}$ atualidade, o grande número de hospitalizações desnecessárias revela, muitas vezes, as conseqüências históricas desse processo que pode até desestruturar as famílias por seguirem as normas de saúde que lhes foram impostas. Essa linha de raciocínio pode elucidar, segundo Costa (1989a), a razão da persistência do mecanismo de tutela familiar, através da atividade médico-hospitalar. A partir do século 19, lidar com a doença tornou-se função dos médicos. Como resultado dessa prática, uma conclusão se impôs: a norma familiar produzida pela ordem médica solicitava, de forma constante, a presença de intervenções disciplinares por parte desses verdadeiros agentes de normalização. Segundo Boltanski (1979), a história da medicina, há mais de um século, é a história contra as práticas médicas populares, com o fim de reforçar a autoridade médica e colocar sob sua jurisdição novos campos abandonados até então ao arbítrio leigo.

De forma semelhante, quando o sofrimento é manifestado na empresa, trabalhadores e gestores não sabem como lidar, ficam sem ação e referencial. Pois, práticas de uma medicina popular, como uso de chás e compra de medicamentos sem receita, são constantemente desaconselhadas. Logo, demandam consulta médica e, em última instância, a hospitalização. Assim, tudo indica que já não há lugar para as práticas de manejo do sofrimento construídas pelos próprios trabalhadores. Outras vezes, representam o manifestado como perturbação mental ou desequilíbrio, uma vez que a ordem médica já se encontra interiorizada. Em conseqüência, tornam-se necessários, no cotidiano do trabalho, a consulta e o parecer de profissionais da saúde, que estão sempre de plantão para corrigir os excessos e as faltas, além de oferecer prescrições e medidas de prevenção. Desse ponto de vista, pode oferecer significativos elementos para este estudo assinalar as origens históricas da psiquiatria, no Brasil, pois, a partir dela, operou-se um deslocamento das práticas médicas com pacientes identificados como "perturbados ou doentes dos nervos", para trabalhadores, famílias e comunidades, sem demandas explícitas de cuidados. Portanto, dar visibilidade ao nascimento dessa psiquiatria tem por objetivo contextualizar uma outra vicissitude do sofrimento, a da psiquiatrização.

Nos anos 30, os psiquiatras brasileiros, definindo-se como higienistas, gradativamente, deslocaram-se da prática asilar tradicional e penetraram nos meios escolar, profissional e social, até então fora dos domínios da psiquiatria, com uma proposta de trabalho apoiada na noção de eugenia. O que é sujo e impuro deve ser mantido distante ou enclausurado para o bem-estar de uma coletividade limpa e pura, de modo que a ordem e o progresso possam estar assegurados. Essa era a lógica implícita. A gradativa travessia da ação médica instituída com 
doentes para uma prática com não-doentes implicava a mudança de um domínio circunscrito para o campo social como um todo. Denominado como prevenção, esse deslocamento tentava subordinar cidadãos sem demandas de cuidado aos critérios de cientificidade da prática médica, incutindo um ideal forjado, muitas vezes, alhures à realidade do sujeito para receber o que se julga melhor para ele (Costa, 1989a).

No campo da "saúde mental", o exercício da prevenção pode ser considerado historicamente falido. No entanto, as noções de sujeito universal e de predição controlada do comportamento - que sustentam as práticas preventivas - permanecem firmes e continuam fundamentando teorias e intervenções nos campos da saúde e do trabalho. Prevenção implica "prédizer", imaginariamente, a existência de uma doença no horizonte e dos mecanismos para evitá-la. Assim procedendo, a medicina fornece elementos lingüísticos para uma comunidade nomear, com vocabulário médico, situações pertencentes ao seu universo cultural (Costa, 1989a). É nesse sentido que se pode entender o encaminhamento de um trabalhador, que se apresenta triste ou com medo, à assistente social, que por sua vez o conduz ao médico do trabalho que o dirige, preventivamente, para o psiquiatra. Nossas observações indicam, como prática mais comum, que esse sujeito receba o diagnóstico de depressão, de fobia ou paranóia, acompanhado de uma prescrição medicamentosa. Dessa forma, dimensões contingentes à existência humana vêm sendo diagnosticados como transtornos psiquiátricos.

Mesmo que na atualidade, nos encontremos temporalmente distantes do ideal eugênico das primeiras décadas do século 20 , a história da psiquiatria permanece exemplar. Ela sinaliza a necessidade de conceder especial atenção ao papel dos contextos na produção de teorias e práticas de atenção à saúde, de modo que não venhamos a reproduzir, no interior das empresas, os erros e equívocos cometidos em nome da ciência e da saúde. Seguindo essa perspectiva, é necessário analisar a passagem da psicopatologia do trabalho para a psicodinâmica dejouriana e as consequêencias da entrada do "espírito científico" nos mecanismos de sobrevivência organizados pelo conjunto dos trabalhadores. O profissional da saúde, como portador de um interesse disseminado em um discurso reconhecido e munido das prescrições dos códigos de ética da sua profissão, não deixa de ser um estranho diante do trabalhador. Este último, mesmo sendo aquele que faz a demanda da intervenção do profissional, é habitualmente um "inocente", pois desconhece os destinos que tomará o seu sofrimento manifestado.

\section{O sofrimento para a psicodinâmica dejouriana}

Interpretar determinadas manifestações do sofrimento no trabalho como pecado, loucura, preguiça, malandragem ou patologia depende daquele que o diagnostica, de sua inserção em determinados discursos, da utilização que faz do vocabulário disponível em sua época, da origem social do trabalhador diagnosticado e do seu capital social. A psicopatologia do trabalho, em meados do século 20, tentou fundar uma clínica de afecções mentais que poderiam ser ocasionadas pelo trabalho. Assim, ela reproduzia o espírito da época, caracterizado por um corpo de conhecimentos extremamente dominado pelo organicismo que vivia, então, o seu apogeu teórico. De forma semelhante, a patologia profissional somática, que gozava de grande prestígio, influenciou as intervenções sobre os danos físico-químico-biológicos dos postos de trabalho. As investigações no campo trabalho-saúde, naquela época, obedeciam a um modelo teórico causal, com vista a encontrar evidências entre doenças mentais e trabalho. Essas observações, por sua vez, não trouxeram os resultados esperados pelos psicopatologistas: destacar e caracterizar a doença mental específica originária da organização do trabalho (Dejours, 1994).

Diante do fracasso dos modelos teóricos da psicofisiologia pavloviana e da patologia do trabalho para demonstrar a correlação entre trabalho e doença mental, uma "nova psicopatologia do trabalho" começou a se delinear na França. Para o psiquiatra francês Christophe Dejours, um dos seus mentores, esse novo modelo foi possível a partir do momento em que a normalidade foi considerada "enigma", tornando-se objeto de estudo. De acordo com essa nova orientação, as investigações não tiveram mais como direção as "doenças mentais", mas as estratégias elaboradas pelos trabalhadores para enfrentar mentalmente a situação do trabalho. Iniciava-se assim, no começo dos anos 80 , sob a influência da psicanálise, a psicodinâmica do trabalho, cujo objeto de estudo era o sofrimento e as defesas contra a doença. Nessa 
época, Dejours concebia o sofrimento como a vivência subjetiva intermediária entre doença mental e o conforto (ou bem-estar) psíquico. Sob esse ângulo, o sofrimento implica, sobretudo, um estado de luta do sujeito contra as forças (ligadas à organização do trabalho) que o empurram em direção à doença mental. Segundo esta concepção, o sofrimento, até então representado como essencialmente negativo, favorecedor da doença, passou a adquirir uma nova significação que abarcava elementos patogênicos e criativos (Dejours, 1994).

O grande mérito de Dejours, ao considerar a significação e o sentido do sofrimento como dimensões essenciais no entendimento da relação saúde-trabalho, foi colocar-se à escuta do trabalhador para compreender o que lhe ocorria. Assim, a fala do trabalhador passou a configurar um privilegiado instrumento de pesquisa e de intervenção (Uchida, 1996). Ao dar voz aos trabalhadores, constatou-se que, entre eles, a doença é geralmente associada à preguiça, vagabundagem ou malandragem. Diante da adversidade, esses trabalhadores tentam dominar a doença de alguma maneira. Partindo desse princípio, Dejours (1992) elaborou o conceito de "ideologia defensiva", como construção social que possibilita dominar e tentar fazer desaparecer da consciência o sofrimento.

É possível constatar, em maior ou menor grau, tanto na psicopatologia do trabalho quanto na psicodinâmica - que buscou investigar as defesas contra a doença - a existência de uma transformação do sofrimento em adoecimento. Segundo a teoria dejouriana, o adoecimento pode acontecer devido a uma "retenção da energia pulsional" por uma situação de trabalho que impede a descarga adequada da carga psíquica. É notória a tentativa da psicodinâmica de reafirmar a centralidade do sofrimento no processo saúde-doença-cuidado. No entanto, essa perspectiva teórica esbarra em pontos críticos. Repete o modelo de explicação causal, ao dicotomizar o sofrimento em criativo e patogênico, e reproduz aspectos que tentava superar em relação à psicopatologia. Nesse sentido, é possível perceber que a psicodinâmica ainda se mantém, um tanto quanto, presa aos modelos termodinâmico e biológico, herdados da psicanálise freudiana e da ergonomia. Fato que fica evidente quando Dejours desenvolve a abordagem econômica do funcionamento psíquico, a partir do modelo médico. Sob essa ótica, a manifestação do sofrimento é interpretada como resultado de um enfraquecimento das es- tratégias coletivas dos trabalhadores e não como uma conseqüência de situações relacionadas ao trabalho. A partir da psicanálise como instrumento de crítica para a organização do trabalho, Dejours pergunta: "há lugar para os trabalhadores serem sujeitos dos seus desejos?” Não se pode esquecer que o desejo, desde Hegel e, posteriormente em Lacan, é sempre desejo do Outro. Mesmo empreendendo consideráveis esforços para fazer avançar no conhecimento da relação saúde-trabalho, a psicodinâmica dejouriana ainda encontra algumas dificuldades, principalmente quando utiliza, de forma vaga e imprecisa, conceitos como "equilíbrio psíquico", "energia psíquica” e "normalidade”, para explicar o sofrimento. Assim, ao polarizá-lo em patogênico e criativo, Dejours reproduz uma longa tradição que, do nascimento da clínica à psicodinâmica do trabalho, transforma o sofrimento em adoecimento, fornecendo elementos teóricos que colaboram na construção da identidade do trabalhador doente.

\section{Identidade de doente: construção e resistência}

O processo de adoecimento conduz, como resultado final, à configuração da identidade de trabalhador-doente. No espaço da fábrica, a construção dessa identidade implica submissão ao discurso médico e sair dessa condição não depende apenas da vontade individual. É preciso a intervenção no âmbito institucional. O próprio discurso da medicina ocupacional produz uma cultura que fornece subsídios para a formação da identidade do doente - entendida como processo pelo qual o indivíduo se reconhece e constrói a significação da sua vida com base no atributo cultural de ser doente - a ponto de excluir outras referências culturais. Se partirmos da definição psicanalítica de que o "sujeito é efeito de linguagem", essa identidade virá caracterizada pelo conjunto de práticas lingüísticas que configuram algumas ações, suscetíveis de apresentar e fazer o sujeito ser representado em seu meio como doente. Os mediadores lingüísticos não bastam. Outros mediadores sociofuncionais contribuem para a constituição dessa identidade, como um conjunto de práticas instituídas, que nas empresas assumem formas de: exames admissionais, periódicos e demissionais; avaliação de desempenho; programas de qualidade de vida, de dependência química e de anti-estresse. 
Esse processo, entretanto, não acontece sem resistências dos atores sociais envolvidos. A insubordinação ao imperativo organizacional da transformação do sofrimento em adoecimento leva à instituição de uma grande diversidade de movimentos. Criam-se diversas alternativas de sobrevivência emocional e material no espaço da fábrica, uma verdadeira cultura do contraafastamento por motivos médicos. A socialização dessas ações entre alguns trabalhadores deixa entrever uma organização política mínima e um nível cultural desorganizado. Essa cultura, em franca contradição à lógica do adoecimento, é capaz de abrigar e sustentar, em seu interior, atores que fazem um duplo movimento de subordinação e insubordinação para driblar essa forma de exclusão. Embora essa cultura possa garantir a permanência no trabalho, não é o suficientemente capaz de evitar o estigma de portador de uma doença. O próprio movimento de permanecer, principalmente entre aqueles que manifestam seu sofrimento, é interpretado como um ato insano. Para uma melhor observação desse movimento, nada mais apropriado do que deixar os próprios trabalhadores falarem.

Os serviços de saúde na empresa, a veiculação do discurso médico e a existência do hospital, como medidas disciplinares, parecem não ser suficientes para que a identidade do trabalhador doente possa se configurar. É necessário construir uma rede de comunicação, envolvendo profissionais da saúde, gestores e familiares do trabalhador que, em comum acordo, decidem num determinado momento o afastamento ou a hospitalização. É o que pode ser constatado na entrevista com Riovaldo, de 29 anos, trabalhador de chão-de-fábrica: A minha internação foi elaborada pelo meu chefe, que ligou para a assistente social, que chamou minha família, dizendo que era preciso me hospitalizar. Eles decidiram me internar. Eu não queria, estava com medo. Eu estava bem, apenas bebendo um pouco mais e chegando atrasado.

Os gestores - extrapolando os objetivos formais da organização referentes à gestão do trabalho - estabelecem elos com os profissionais da saúde para capturar o trabalhador, numa complexa trama em torno do processo trabalho-doença-cuidado. Sem o apoio familiar, essa estratégia disciplinar não seria possível. A família, uma vez acionada e sentindo-se impotente diante das manifestações do sofrimento do trabalhador, incorpora a ordem médica e autoriza a hospitalização. Os supervisores difi- cilmente aceitam atrasos, principalmente, nos casos já tornados públicos de abuso do álcool. Sua mais árdua missão é a manutenção da disciplina e o controle de horários, objetivos mais importantes do que as metas de produtividade. No entanto, chegar atrasado é tentar reivindicar para si próprio o controle de um aspecto de sua identidade e de seu autogoverno. É uma forma de se ver livre do tempo institucional, situação intolerável para uma empresa. Já, o gole de álcool parece constituir-se uma estratégia multifacetada de extraordinária importância para lidar com as condições do chão-de-fábrica. É usado, geralmente, para lidar com o tédio, o medo e o cansaço. Serve para enfrentar situações difíceis e problemas, um "verdadeiro remédio" para quase tudo, segundo a opinião do citado trabalhador.

É possível detectar estratégias de resistência, mesmo em situações em que o trabalhador se encontra bastante fragilizado. É o caso de uma atendente comercial com diagnóstico de "distúrbio de estresse pós-traumático" por manifestar ansiedade, após ter sofrido dois assaltos em seu posto de atendimento, no intervalo de seis meses, e encontrar dificuldades em readaptar-se. A convivência com os colegas a faz constatar, rapidamente, que vinha sofrendo discriminação por apresentar um comportamento diferenciado. No entanto, ela não percebe que a manifestação do seu sofrimento revela a periculosidade da sua função e quebra as estratégias defensivas dos colegas que tentam minimizar a percepção do sofrimento. A sua angústia lhes faz lembrar aquilo que gostaria de esquecer e revela um perigo real. Daí a pressão para se igualar ao conjunto, na forma de lidar com as ameaças a que o cargo a expõe. Por não conter a própria apreensão, como os demais parecem conseguir, foi obrigada a se afastar, novamente, do seu posto. O grupo profissional armado da ideologia defensiva elimina aquele que não consegue suportar o risco (Dejours, 1992). Entretanto, a nossa entrevistada procura resistir às situações que podem transformá-la em doente. Sua consciência crítica e sua formação universitária oferecem alguns subsídios, como é possível constatar quando afirma: $O s$ colegas de trabalho resistiram. Até me falam que eu devia esquecer tudo. Fazer como eles, trabalhar. É terrível tomar antidepressivo. Passa de uma questão de trabalho para ser pessoal. Todo mundo te pára na rua e pergunta se você melhorou. As pessoas te enxergam como doente mental. (M., 22 anos, atendente comercial). 
Revelar ao médico apenas aspectos positivos da situação em que se encontra e ocultar a interrupção da medicação, por decisão própria, têm se constituído, segundo constatamos em nossa investigação, formas de enfrentar as práticas institucionais que podem vir a transformar o sofrimento em adoecimento e, conseqüentemente, em afastamento. A renitência em fornecer informações do estado de saúde acontece, sobretudo, pelo fato de o trabalhador perceber o poder médico, que ignora o seu sofrimento e reconhece apenas a doença. Para enfrentar a autoridade médica, aprendeu que precisa apresentar-se como doente educado, com semblante de obediente e ingênuo. Como afirma a mesma entrevistada, no final do primeiro mês de afastamento: Não tomo mais remédio. Eu não comento isso com eles (médicos). Tenho medo deles aumentarem a dose, poderiam pensar que estou piorando, porque estou resistente. Chego no consultório: está tudo ótimo! Se não, você acaba se tornando um doente. Você vai internalizando o que as pessoas acham.

Apresentar-se como doente ou não, como no caso da citada trabalhadora, é uma questão de posição do sujeito diante das circunstâncias e da sua inserção em um dado discurso. Não há fato patológico, afirma Nietzsche (1978). Para o filósofo alemão, nem a saúde nem a doença são entidades; em última instância, são valores, da mesma forma que o bem e o mal, o verdadeiro e o falso. Emitir um diagnóstico de estresse pós-traumático e uma comunicação de acidente de trabalho (CAT), para aqueles que sofreram assaltos no trabalho, não implica, necessariamente, que esses estejam doentes. Mesmo que eles apresentem ansiedade e dificuldades de permanecerem em seus postos, sofrimento e doença não se igualam. A doença depende tanto de quem tem quanto de quem a diagnostica, ou de onde se diagnostica (Camargo Jr., 1992). A partir do sujeito, como construto teórico psicanalítico, doença pode significar saúde e vice-versa. A saúde é aquilo que pode ser útil a um homem ou a uma tarefa, ainda que para outros signifique doença. Não fui um doente nem mesmo por ocasião da minha maior enfermidade (Nietzsche, 1978).

A saúde e a doença não podem ser conceituadas apenas pela ausência ou pela presença de determinados agentes etiológicos e sintomas. Manifestar taquicardia, sudorese, transtornos do sono e da alimentação, como é o caso da nossa entrevistada, não autoriza diagnosticá-la como doente. Como observa Minayo
(1996), os sintomas e os agentes etiológicos trazem uma carga histórica, cultural, política e ideológica e não podem ser contidas apenas numa fórmula numérica ou num dado estatístico. Da mesma forma, o processo saúde-doença não pode ser reduzido a um conjunto de significados determinado pela cultura da empresa e pelo discurso médico hegemônico. É necessário pensar nesta determinação, para além dos sujeitos do significado, aproximando-a do conceito de sujeito do significante, conforme a concepção lacaniana. Ela deve ser pensada, também, como determinação da ordem da linguagem, entendida como "verdadeiros Outros". A partir das contribuições da psicanálise, devese reconhecer que tanto o "doente" quanto o "não-doente" não existem em si, como um dado da "natureza" ou da cultura, mas como sujeitos que recebem a denominação de doentes, vinda da medicina, e que respondem a esta como doentes ou como não-doentes (Brant, 2001). É na condição de efeitos de práticas lingüísticas que alguém se identifica e se reconhece como doente ou não-doente. Para tanto, é necessário que os mediadores lingüísticos se materializem através das práticas ou mecanismos institucionais, como licenças médicas, inserção em serviços de saúde da empresa, hospitalização e aposentadoria por invalidez.

Verificamos, também, que o sofrimento se apresenta sob a forma de humor. Nesse caso, o trabalhador constrói um subterfúgio para manifestar seu sofrimento, sem que o mesmo apareça como tal. Essa estratégia parece evitar que ele sofra o destino do adoecimento. $\mathrm{O}$ chão-defábrica surge como um terreno fértil para as "brincadeiras" que, segundo nosso entendimento, são formas veladas de desrepressão e de manipulação. Vejamos como um gestor, que se julga muito sério e exigente, faz uso da brincadeira: Em alguns momentos eu brinco. É quando me sinto triste, sozinho. No momento que sou sério, sou menos aceito. Cobro, exageradamente, dos meus funcionários. Isto me trás muito cansaço, na maioria das vezes. O brincar me alivia e me torna mais aceito. A brincadeira não é forçada, é parte do meu jeito de ser (Gracindo Jr., 39 anos, supervisor).

Ao tentar fazê-la parecer natural, esse trabalhador recusa reconhecer a sua brincadeira como uma estratégia. Nem poderia, pois ela é parte de uma irreverente conduta, uma vez que por esse meio o gestor manifesta seu sofrimento, diverte e subverte o imperativo organizacional que não admite o sofrimento em seu inte- 
rior. Essa prática permite a figuração do sofrimento, mesmo em situações marcadas pela rigidez, como é o caso da reunião com a diretoria regional. Segundo esse entrevistado, ninguém acredita em sua timidez e dificuldade de relacionamento, que tanto o fazem sofrer, exatamente, devido às brincadeiras. É necessária uma habilidade transgressiva e um certo knowhow para expressar os sentimentos dessa forma. A risada, a conversa e o comportamento de pilhagem são bastante eficazes, mas não totalmente, para vencer o tédio - um tédio aumentado por seu próprio êxito (Willis, 1991).

\section{Considerações finais}

Quando nos perguntávamos pelos elementos que compõem o processo de transformação do sofrimento em adoecimento, uma de nossas hipóteses era de que a produção e a reprodução de determinados discursos no campo da saúde ocupavam um importante lugar. Muitos desses discursos, sustentados por reconhecidos intelectuais e respeitados profissionais do campo da saúde, não são apenas produtos, mas eles próprios também produzem uma cultura: a do sujeito doente. Não obstante, a compreensão essencialmente lingüística desse processo não é suficiente. A reprodução do discurso do adoecimento precisa de se "imaginarizar" em práticas reconhecidas socialmente, como os exames, a medicalização e a internação hospitalar.

Ao longo da trajetória que vai do nascimento da clínica à psicodinâmica dejouriana, embora houvesse um desejo de mudança, de renovação dessas práticas e empenho para acertar, cometeram-se sérias distorções, violências e exclusões, em nome da ciência, da saúde e do bem-estar dos trabalhadores.

Nesses dois séculos da "medicina científica", a fala e a memória do paciente se tornaram objetos de interesse apenas como conjunto de dados informativos para elaboração de diagnósticos, jamais como registros vivos de uma história de trabalho. Para o olhar clínico, a história não está no sujeito, mas em seus prontuários, basta consultá-los. Da mesma forma, é suficiente lembrar a seqüência dos sintomas, o aparecimento de seus caracteres atuais, as medicações já aplicadas e as intervenções médicas sofridas. A palavra pela qual o sujeito se faz presença no mundo não é relevante, pelo contrário, pode atrapalhar. $\mathrm{O}$ olhar sem a escuta faz da relação médico-paciente uma investiga- ção asséptica, sem verdadeiro diálogo. A medicina para ser científica tentou anular o que há de sujeito no paciente e no profissional, buscando transformá-los, respectivamente, em objeto e instrumento.

Partir do nascimento da clínica para tentar assinalar pontos que poderiam dar sustentação à tese da transformação do sofrimento em adoecimento constituiu uma arriscada e ousada tarefa para um artigo. Apenas limitamo-nos a apontar algumas constatações. De forma semelhante aos colegas do século 19, na atualidade, determinados profissionais da saúde parecem não perceber que seus atos contribuem para a produção da identidade do sujeito doente. No entanto, assinalar pontos da história parecia insuficiente. Ter dado voz aos trabalhadores demonstrou ser um recurso apropriado. Permitiu verificar que a articulação entre profissionais da saúde e gestores para a manutenção da ordem no espaço da empresa, através do adoecimento, não se faz sem a cumplicidade da família. E que a "brincadeira", por exemplo, constitui uma estratégia para expressar o sofrimento sem correr os riscos do destino do adoecimento.

A estratégia utilizada permitiu reconhecer que, no espaço da fábrica pós-industrial, não parece haver lugar para o sofrimento. A tristeza e o medo, ao não serem reconhecidos como dimensões próprias do ato de viver, são transformados em depressão e fobia. Numa cultura marcada pela imediaticidade, o sofrimento é visto como um sinal de fraqueza. Entendemos que não é tanto a doença, mas sim o processo do adoecimento que abre maiores possibilidades de afastamento do trabalho. O adoecimento só é possível devido à existência de um discurso e uma prática que afirmam: "você está doente"; como se a presença da doença e do ser doente pertencessem à mesma categoria. Assim, entre o visível e o enunciável da relação do médico com seu paciente, é preciso perguntar: e o que se fala se dá a partir do que se vê? Ou se enxerga apenas o que já existe como discurso? Se assim for, não se vê, reconhece-se. Aquilo que se fala ao paciente sobre a sua condição se baseia no que se reconhece nele. Logo, é possível deduzir que o médico apenas vê ilusoriamente o trabalhador, pois a doença diagnosticada não está propriamente nele, tem origem em outro lugar: na instituição do discurso médico que conduz à construção de trabalhadores doentes. Sendo assim, a quem pode interessar a produção de trabalhadores incapacitados institucionalmente? 


\section{Referências bibliográficas}

Boltanski L 1979. As classes sociais e o corpo. Ed. Graal, Rio de Janeiro.

Brant LC 2001a. Sujeito e sofrimento entre trabalhadores que ocupam cargo gerencial. Dissertação de mestrado, Universidade Federal de Minas Gerais, Belo Horizonte.

Brant LC 2001b. O indivíduo, o sujeito e a epidemiologia. Ciência \& Saúde Coletiva 6(1):221-231.

Camargo Jr K 1992. (Ir)racionalidade médica: os paradoxos da clínica. Physis Revista de Saúde Coletiva. 2:203-228.

Costa JF 1989a. História da psiquiatria no Brasil. Ed. Xenon, Rio de Janeiro.

Costa JF 1989b. Ordem médica e norma familiar. Ed. Graal, Rio de Janeiro.

Costa JF 1992. A inocência e o vício. Ed. Relume-Dumará, Rio de Janeiro.

Dejours C 1992. A loucura do trabalho. Ed. Cortez, São Paulo.

Dejours C 1994. Psicodinâmica do trabalho: contribuições da Escola Dejouriana à análise da relação prazer, sofrimento e trabalho. Ed. Atlas, São Paulo.

Dejours C 1996. Uma nova visão do sofrimento humano nas organizações, pp. 149-173. In J Chanlat. $O$ indivíduo na organização. Ed. Atlas, São Paulo.

Foucault M 1998. O nascimento da clínica. Ed. Forense, Rio de Janeiro.

Foucault M 1979. Microfísica do poder. Ed. Graal, Rio de Janeiro.

Freud S (1920). Além do princípio do prazer. Ed. Imago, Rio de Janeiro. (Edição standard brasileira das obras psicológicas completas de Sigmund Freud, 28).

Herzlicch C \& Pierret J 1987. Illness and self in society. Johns Hopkins University Press, Baltimore.

Jardim S 1994. Processo de trabalho e sofrimento psíquico: o caso dos pilotos do Metrô carioca. Tese de doutorado, Instituto de Psiquiatria e Saúde Mental, Universidade Federal do Rio de Janeiro, Rio de Janeiro.
Marquez C 1994. Le mal cronique. Autrement (142)fev.:34-39.

Merlo A 1999. A informática no Brasil: prazer e sofrimento no trabalho. Ed. Universidade/UFRGS, Porto Alegre.

Minayo MCS 1996. O desafio do conhecimento: pesquisa qualitativa em saúde. Hucitec-Abrasco, São PauloRio de Janeiro.

Nietzsche F 1978. O nascimento da tragédia no espírito da música. (Os Pensadores) Ed. Abril Cultural, São Paulo.

Oliveira P 1998. O sofrimento psíquico e o trabalho hospitalar: um estudo de caso realizado em um hospital no Pará. Dissertação de mestrado, Escola Nacional de Saúde Pública, Fiocruz, Rio de Janeiro.

Palácios M 1993. Trabalho hospitalar e saúde mental: o caso de um hospital geral e público no Município do Rio de Janeiro. Tese de mestrado. Centro Biomédico, Universidade do Estado do Rio de Janeiro, Rio de Janeiro.

Palácios M 1999. Sofrimento psíquico e trabalho: um estudo de caso sobre o sofrimento psíquico dos trabalhadores e suas relações com o trabalho de caixa em uma grande empresa estatal bancária. Tese de doutorado. Faculdade de Engenharia de Produção, Universidade Federal do Rio de Janeiro, Rio de Janeiro, 156 pp.

Ricoeur P 1994. La souffrance n'est pas la douler. Autrement (142) fev. p. 58-69.

Uchida S 1996. Temporalidade e subjetividade no trabalho informatizado. Tese de doutorado em Psicologia Social, Instituto de Psicologia, Universidade de São Paulo, São Paulo.

Willis P 1991. Aprendendo a ser trabalhador. Ed. Artes Médicas, Porto Alegre.

Artigo apresentado em 11/8/2003

Aprovado em 11/9/2003

Versão final apresentada em 29/10/2003 